\title{
ANALISIS PESAN KOMUNIKASI \\ DALAM SURAT LUQMAN AYAT 12-19
}

\author{
Ahmad Jasyadi \\ Email: jasyadi95@gmail.com
}

\begin{abstract}
This paper analyzes Luqmanul Hakim's communication message against his son in the Qur'an of Luqman's letter verses 12-19 based on Tafsir Jalalain. In addition, this paper also aims to find out how the opinion of the scholars of the Tafsir (Jalaluddin al-Mahalli and Jalaluddin as-Suyuthi) about Luqman's message, especially in the context of the verse in Luqman's letter, to broaden the knowledge of the meaning of Luqmanul Hakim's communications message. This paper is, a research that has been done in literature research. Message analysis procedures using Qualitative Content. Methods in religious studies or Islamic history contained in the Qur'an that use $m a^{\prime} t s u r$ and $r a^{\prime} y$. This study uses a qualitative type because it deepens deeper into the message of a Luqmanul Hakim, especially in the context of verses 12-19 of Luqman's letter with content analysis.
\end{abstract}

Keywords: Analysis, Message, Communication, Interpretation of Jalalain. 


\begin{abstract}
Abstrak
Paper ini menganalisis pesan komunikasi Luqmanul Hakim terhadap anaknya dalam al-Qur'an surat Luqman ayat 1219 berdasarkan Tafsir Jalalain. Selain itu, Paper ini juga bertujuan untuk mengetahui bagaimana pendapat ulama tafsir (Jalaluddin al-Mahalli dan Jalaluddin as-Suyuthi) tentang pesan Luqman khususnya dalam konteks ayat dalam surat Luqman, agar lebih luas pengetahuan tentang makna pesan komunikasi Luqmanul Hakim. Paper ini merupakan Penelitian yang telah dilakukan termasuk dalam penelitian pustaka.Prosedur analisis pesan yang menggunakan model Content Analisys Kualitatif atau analisis isi kualitatif.Metode dalam penelitian agama atau sejarah islam yang terdapat dalam al-Qur'an yang menggunakan ma'tsur dan ra'y. Penelitian ini menggunakanjenis kualitatif karena menyelami lebih mendalam tentang pesan seorang Luqmanul Hakim, khususnya dalam konteks ayat 12-19 surat Luqman dengan analisis isi.
\end{abstract}

Kata kunci: Analisis, Pesan, Komunikasi, Tafsir Jalalain

\section{A. Pendahuluan}

Komunikasi merupakan alat untuk mempermudah memahami suatu makna dalamkehidupan seharihari.Dimanapesanyangdisampaikan oleh seorang komunikator kepada komunikan terdapat timbal balik, sehingga komunikasi dapat disebut efektif. Dalam al-Qur'an juga, komunikasi yang terjalin sangat efektif dan besar kontribusinya bagi kehidupanmanusia dengan Sang Khaliq. Menggunakan komunikasi, setiap orang bisa saling memahami satu dengan yang lainnya.Kemudian komunikasi juga memiliki cara agar efek yang disampaikan bisa dirasakan dengan baik oleh komunikator kepada komunikannya.

Prinsip komunikasi dalam alQur'an ditemukan dalam lafazh "Qaulan" (perkataan). Ada 6 istilah Qaulan yang menjadi panduan Islami dalam berkomunikasi: Qaulan Sadida (QS. An-Nisa:9), Qaulan Baligha (QS. An-Nisa': 63), Qaulan Ma'rufa (QS. Al-Baqarah: 235; QS. An- Nisa': 58 8; QS. Al-Ahzab: 32), Qaulan Karima (QS. Al-Isra': 23), Qaulan Layyina 
(QS. Thaha: 44), Qaulan Maysura (QS. Al-Isra’: 28). ${ }^{1}$

Dari sekian prinsif komunikasi yang menjadi acuan dalam kisah Luqman adalah "Qaulan Layyina" (Lemah-Lembut). Allah SWT berfirman

"Maka berbicaralah kamu berdua kepadanya dengan (Qaulan Layyina) kata-kata yang lemahlembut..." (QS. Thaha: 44).

Qaulan Layyina berarti pembicaraan yang lemah-lembut, dengan suara yang enak didengar, dan penuh keramahan, sehingga dapat menyentuh hati.Dalam Tafsir Ibnu Katsir disebutkan, yang dimaksud Layyinan ialah kata-kata sindiran, bukan dengan kata terus terang atau lugas, apalagi kasar. ${ }^{2}$

Di dalam al-Qur'an Surah Luqman (Arab: الُقََْان Luqman) merupakan surah ke-31. Surah ini terdiri dari atas 34 ayat dan termasuk golongan surah-surah Makkiyah(diturunkan di Makkah). Surah ini diturunkan setelah surah As-Saffat. Nama Luqman diambil dari kisah tentang Luqman yang diceritakan dalam surah ini tentang bagaimana dialog/komunikasi ia

1 Kementrian Agama RI, Al-Qur'an dan Terjemahannya Edisi Literasi (Solo: Tiga Serangkai Pustaka Mandiri, 2015)

2 Anty, 2017., "prinsip komunikasi islam", dalam http://www.risalahislam.com. Di akses tanggal 28 September 2017 pukul 14.10 wita dalam memberikan pesan atau nasihat kepada anaknya.

Dalam kisah Dialog Seorang Luqman dengan anaknya ketika mengatakan "Yaa Bunayya" menggunakan prinsif komunikasi QaulanLayyinan (ucapan yanglemahlembut menyentuh hati). Dengan Qaulan Layyinan, hati komunikan (orang yang diajak berkomunikasi) akan merasa tersentuh dan jiwanya tergerak untuk menerima pesan komunikasi kita dan cenderung sangat efektif untuk diterima dalam kehidupan sehari-hari, karena zaman sekarang ini nasihat atau pesan sangat jarang disadari dan dicermati oleh sebagian masyarakat.

Pesan yang terkandung dalam kisah Luqman ini adalah bagaimana menghidupkan kembali nilai-nilai ketauhidan dan aspek hasanah/ kebajikan dalam setiap saat.Ada beberapa ayat dalam al-Qur'an yang mengabadikan pelajaran Luqman terhadap anaknya, salah satunya adalah firman Allah:

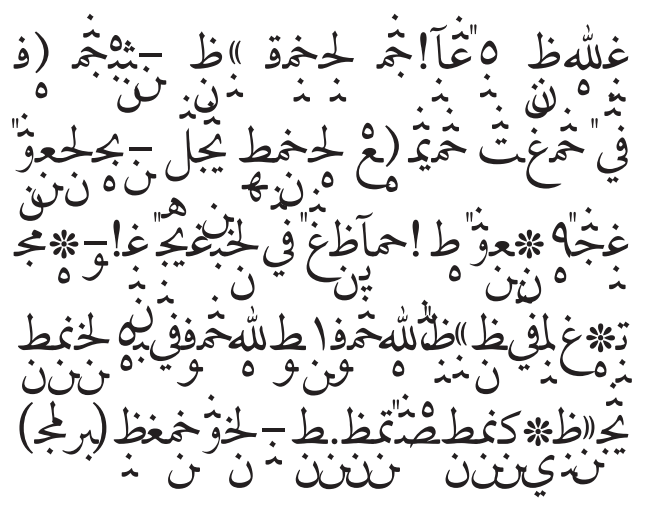


Artinya: "Dan (ingatlah) ketika Luqman berkata kepada anaknya, di waktu ia memberi pelajaran kepadanya: "Wahai anakku, janganlah kamu mempersekutukan Allah, Sesungguhnyamempersekutukan (Allah) adalah benar-benar kezaliman yang besarm. ${ }^{3}$

Asbabun Nuzul dari surat Luqman ayat 13 ini adalah ketika ayat ke-82 dari surat al-An'am diturunkan, Dalam hadits Bukhari, dari Qutaibah, dari Jarir, dari AlA'masy, dari Ibrahim, dari 'Alqomah, dari 'Abdullah radhiyallahu 'anhu, beliau menyebutkan ayat,

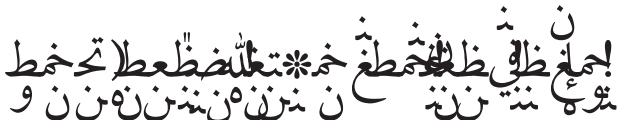
Artinya: "orang-orangyangberiman dan tidak mencampuradukkan iman mereka dengan kedzaliman".

Ketika disebutkan ayat ini, para sahabat pun menjadi khawatir. Mereka berkata:

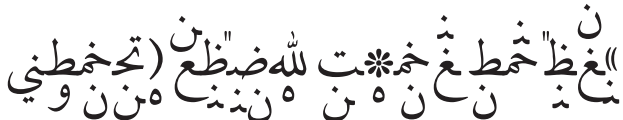

Artinya:"(Wahai Rasul), siapakah yang tidak mencampurkan keimanannya dengan kesyirikan?" Lantas Rasul shallallahu 'alaihi wa sallam bersabda.

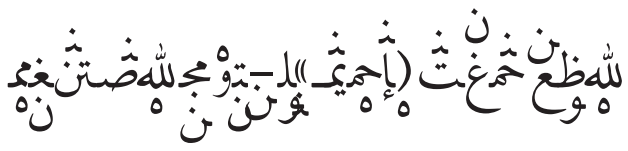

3 QS. Luqman: 13 (al-Qur'an dan terjemahan edisi transliterasi) hlm. 412

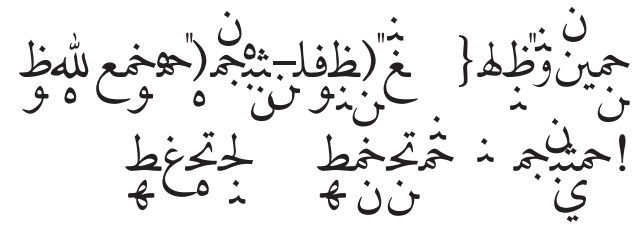

Artinya;"Itu bukanlah kezholiman seperti yang kalian sangkakan. Tidakkah kalian pernah mendengar nasehat Lukman pada anaknya, "Hai anakku, janganlah kamu mempersekutukan Allah, sesungguhnya mempersekutukan (Allah) adalah benar-benar kezaliman yang besar." (HR. Bukhari no. 3360)

\section{B. Pengertian Pesan Komunikasi}

Membicarakan pesan (massage) dalam proses komunikasi, kita tidak bisa melepaskan diri dari apa yang namanya simbol dan kode, karena pesan yang dikirim komunikator kepada penerima terdiri atas rangkaian simbol dan kode. ${ }^{5}$

Pesan merupakan seperangkat simbol verbal/non verbal yang mewakili perasaan, nilai, gagasan atau maksud sumber tadi.Menurut Onong Effendy, menyatakan bahwa pesan adalah

"Suatu komponen dalam proses komunikasi berupa paduan dari pikiran dan perasaan seseorang

4 Mudjab Mahali, Asbabun Nuzul, (Jakarta: RajaGrafindo Persada, 2002), hlm. 660

5 Hafied Cangara, Pengantar Ilmu Komunikasi, (Jakarta: RajaGrafindo Persada), hlm. 111 
dengan menggunakan lambang, bahasa/lambang-lambang lainnya disampaikan kepada orang lain".

Sedangkan Abdul Hanafi menjelaskan bahwa pesan itu adalah produk fiktif yang nyata yang dihasilkan oleh sumber. Kalau berbicara maka "Pembicara" itulah pesan, ketika menulis surat maka "tulisan surat" itulah yang dinamakan pesan.

Pesan mempunyai tiga komponen : makna, simbol yang diguankan untuk menyampaikan makna, dan bentuk atau organisasi pesan. Simbol terpenting adalah kata kata (bahasa), yang dapat merepresentasikan objek (benda), gagasan, dan perasaan, baik ucapan (percakapan, wawancara, diskusi, ceramah, dan sebagainya) ataupun tulisan (surat, esai, artikel, novel, puisi, pamflet, dan sebagainya). ${ }^{7}$

\section{B. Teori Komunikasi dalam al- Qur'an Surat Luqman Ayat} 12-19

Dalam kajian surat Luqman ayat 12-19 tersebut, penulis menggunakan Teori komunikasi yaitu teori S-O-R (Stimulus Organism Respon). Teori S-O-R sebagai singkatan dari

6 Ibid.

7 Danus Ardiansah, Hakikat Dalam Pesan Komunikasi, dalam http://www.academia. $\underline{\text { edu/9036594 di akses tanggal } 2 \text { oktober } 2017 \text { pukul }}$ 06.20 wita
Stimulus-Organism-Respon, semua berasal dari psikologi. Kemudian menjadi teori komunikasi, tidak mengherankankarenaobjekmaterial dari psikologi dan ilmu komunikasi adalah sama, yaitu manusia yang jiwanya meliputi komponenkomponen: sikap, opini, perilaku, kognisi, afeksi, dan konasi. ${ }^{8}$

Menurut stimulus response ini, efek yang ditimbulkan adalah reaksi khusus terhadap stimulus khusus, shingga seseorang dapat mengharapkan dan memperkirakan kesesuaian antara pesan dan reaksi komunikan. Jadi unsur-unsur dalam model ini adalah:

Pesan (stimulus)

Komunikan (organism)

Efek (response)

Dalam proses komunikasi berkenaan dengan perubahan sikap adalah aspek "how" bukan "what" dan "why". Jelasnya how to communicate. Dalam hal ini how to change the attitude, bagaimana mengubah sikap komunikan.

Dalam proses perubahan sikap tampak bahwa sikap dapat berubah, hanya jika stimulus yang menerpa benar-benar melebihi semula.

8 Onong Uchana Efendy, Ilmu, Teori Dan Filsafat Dan Teori Komunikasi, (Jakarta: Citra Aditya Bakti), hlm. 254 
Mar'at dalam bukunya "Sikap manusia, perubahan serta pengukurannya, mengutip pendapat Havland, Janis, dan Kelley yang menyatakan bahwa dalam menelaah sikap yang baru ada tiga variabel penting. ${ }^{9}$

- Perhatian

- penerimaan

- Pengertian

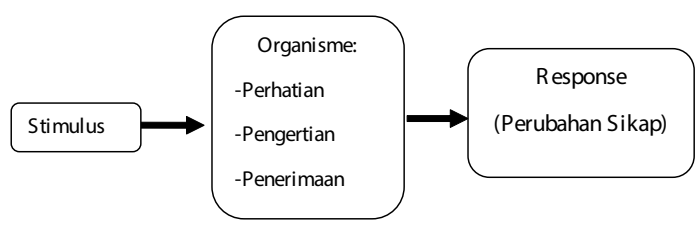

Gambar.1: Skema teori S-O-R

Stimulus atau pesan yang disampaikan kepada komunikan mungkin diterima atau mungkin tidak. Komunikasi akan berlangsung jika ada perhatian dari komunikan. Proses berikutnya komunikan mengerti. Kemampuan komunikan inilah yang melanjutkan proses berikutnya.Setelah komunikan mengolahnya dan menerimanya, maka terjadilah kesediaan untuk mengubah sikap. ${ }^{10}$

Dari penjelasan teori ini, dapat simpulkan bahwa hal yang menjadi patokan atau arah dalam meneliti terkait dengan kisah Luqmanul Hakim dalam al-Qur'an yang berdialog dengan anaknya yang

\footnotetext{
9 Ibid, hlm. 256

10 Ibid.
}

menghasilkan pesan yang bermakna dan respon dari anaknya dalam pesan yang diberikan oleh Luqmanul Hakim. ${ }^{11}$

Dari pesan Luqman diatas sangat perlu diterapkan dalam kehidupan sekarang ini, seperti ketauhidan, cara sholat yang benar, bagaimana bersabar dalam ujian, dan menghindari sikap sombong dan angkuh terhadap sesama. Namun realitanya sekarang kita lihat banyak yang berbalik arah dengan pesan Luqman, mencegah kemungkaran dan sebagainya.

Perintah sholat juga sangat jauh dari arahan yang diberikan orang tua kepada anak-anaknya. Sekarang anak-anak lebih kenal dunia artis daripada kisah sejarah Islam, itu semua karena tuntunan orang tua tidak ada tertanam pada diri anak khususnya dalam memberikan pesan atau nasihat. Di dalam pesan komunikasi tersebut.

\section{Larangan syirik atau Menyekutukan Allah}

Dalam al-Qur'an surat Luqman ayat 12 dijelaskan bahwa, anjuran pertama yangdiajarkan oleh Luqman kepada anaknya adalah larangan syirik atau menyekutukan Allah. Ini adalah pesan yang sangat mendalam

11 Kementrian Agama RI, Al-Qur'an Dan TerjemahanEdisi Trasliterasi, (Solo: Tiga Serangkai Pustaka Mandiri, 2015), Hlm. 412 
dan menjadi pendidikan utama yang harus diberikan kepada anak, agar nantinya tidak salah dalam mengEsakan Allah. Syirik yang dimaksud adalah syirik atau menyekutukan Allah dengan sesuatu apapun..

\section{Berbakti Kepada Kedua Orang Tua}

Kata "Ihsan" dalam bab temuan dan paparan data adalah merupakan semua aspek perilaku yang bersifat positif atau kebaikan, terlebih khusus kepada orang tua. Pesan komunikasi kedua Luqmanul Hakim ini merupakan pesan yang sangat penting. Sebab, jika sesorang tidak berbakti alias durhaka, maka sudah jelas kehidupannya akan suram dan lebih parah lagi tempatnya di neraka.

\section{Anjuran untuk Mendirikan Sholat}

Sholat merupakan benteng ummat islam, sebagai perisai ummat islam. Sholat merupakan sebagai tiang agama yang memperkuat keimanan seorang insan dan sholat merupakan senjata menuju syurganya Allah SWT. Seperti yang penulis temukan pada bab temuan dan data bahwa Sholat menurut bahasa berarti "Doa". Secara bahasa saja sudah mengandung makna yang pentingyaitu suatupermohonan.Jadi dengan melakukan atau mendirikan sholat seolah kita meminta atau memohon kepada Allah SWT apa yang kita pinta.

Kemudian diperjelas lagi dengan pengertian menurut istilah bahwa sholat merupakan suatu pekerjaan yang diawali dengan takbir (Allahu Akbar) dan diakhiri dengan salam (Assalamu'alaikum Warahmatullahi Wabarokatuh) dengan syarat-syarat tertentu.

Dasar diperintahkannya mendirikan sholat sudah diterangkan dalam al-Qur'an yang mulia salah satunya pada surat Luqman ayat 17 ,

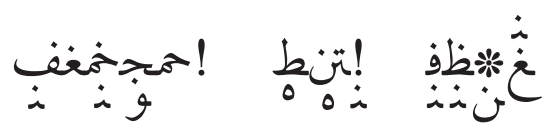
Artinya: "Wahai Anakku ! Laksanakanlahsholat.(QS. Luqman :17).

Hikmah dianjurkan atau difardhukannya sholat adalah supaya manusia bebas dari kekufuran dan menyebabkan ketundukan atau kepasrahan kepada AllahSWT. Sholat juga merupakan suatu amalan yang paling utama dihisab nanti pada hari kiamat. Oleh karenanya, Luqman sangat menganjurkan anaknya untuk melaksanakan sholat.

Dalam sabda Nabi SAW yang berbunyi,

"Amal yang pertama kali dihisab adalah Sholat. Jika sholatnya bagus maka amalnya yang lain juga bagus, tetapi jika sholatnya rusak maka amal yang lainnya juga rusak. 
Sholat merupakan benteng utama untuk memperkuat keimanan dan jalan menuju syurganya Allah SWT. Dalam sholat terdapat hal yang sangat luar biasa, salah satunya jika dilihat dari ilmu kesehatan bahwa ketika melaksanakan sholat, disana terdapat banyak gerakan yang merupakan terapi bagi kesehatan manusia.

Dibalik pentingnya sholat, penulis melihat realita sekarang banyak orang yang meninggalkan sholat padahal sholat sudah menjadi rukun dan tidak bisa ditinggalkan. Dalam sholat juga terdapat banyak keajaiban maupun kesehatan yang didapatkan.

Ini tak lain dari kurangnya ilmu yang terdapat dalam masyarakat awam khususnya. Penulis merasa prihatin melihat realita, banyak orang meninggalkan sholat terutama kaum muda. Jika pemuda tidak sholat maka rusaklah tiang-tiang suatu kehidupan. Untuk itu penulis mencoba berusaha membangkitkan kembalinilai-nilaiyangtelah Luqman pesan kepada anaknya yaitu sholat di tengah-tengah masyarakat.

\section{Amar Ma'ruf Nahi Mungkar}

Amar ma'ruf nahi mungkar sering didengar tetapi jarang untuk memaknainya. Dikalangan masyarakat awam kata amar ma'ruf nahi mungkar lebih populer dengan kekerasan, nyatanya tidak. Amar ma'ruf adalah kalimat dalam bahasa arab, dalam bahasa indonesia dikenal dengan menyuruh kepada kebaikan dan nahi mungkar adalah mencegah dari kemungkaran, keburukan, kejahatan, kejelekan dan lainnya.

Perlu diketahui bahwa mengajak kepada kebaikan dan mencegah kepada kemungkaran bisa membedakan antara Muhtasib, Muhtasab 'alaih, Muhtasab Fih dan Nafsul Ihtisab. Muhtasib adalah orang yang menyeru atau komunikator, Muhtasab 'alaih adalah sasaran orangnya atau komunikan, Muhtasab Fih adalah perbuatan yang dilakukan dan Nafsul Ihtisab adalah cara untuk amar ma'ruf nahi mungkar.

Jika sudah mengetahui apa itu amar ma'ruf nahi mungkar maka sudah seharusnya untuk menyemarakkan dikalangan masyarakat. Itulah pesan yang disampaikan oleh Luqman sang bijaksana kepada anaknya.

Amar ma'ruf dan nahi mungkar merupakan amanah yang harus ditegakkan di tengah-tengah masyarakat. Dilihat dari realita sekarang amar ma'ruf lebih mudah daripada nahi mungkar. Sebagian orang mengatakan mengatakan demikian karena ketika ingin melakukan kebaikan tidak ada kendalanya justru mencegah kebathilan, kemungkaran, kejelekan, 
kejahatan sulit dan berat bagi pelaku, karena itu banyak kendala. Namun baik itu ringan maupun berat dan sulit, tetap itu adalah amanah yang harus ditegakkan.

Nahi mungkar merupakan amanah yang memiliki tingkatan yang dalam mengatasinya. Seperti dalamhaditsyangpenuliskutipdalam bab temuan data bahwa mencegah dengan tangan itu haruslah bagi penguasa dan mencegah dengan lisan itu bagi para ulama, para kiyai, orang-orang yang berilmu dan mencegah dengan hati adalah bagi semua orang yang beriman.

\section{Sabar dalam Menghadapi Ujian Hidup}

Di dalam tafsir Jalalain juga dijelaskan secara singkat bawa sabar yang dimaksud adalah sabar dalam melakukan amar ma'ruf nahi mungkar. Dijelaskan juga dalam hadis yang ditulis oleh Jalaludin Assuyuthi dalam bukunya yang berjudul Terjemah Lubabul Hadis (400 hadits) bahwa Nabi SAW bersabda,

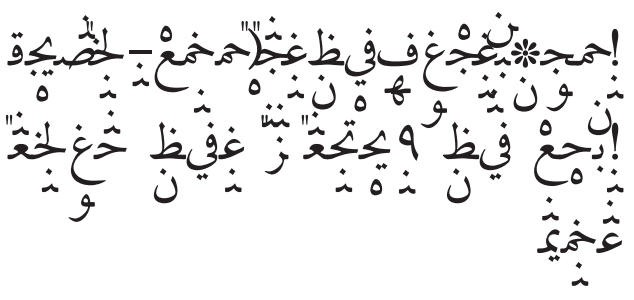

Artinya: "Sabar adalah wasiat dari wasiat-wasiat Allah Taala dibuminya. Barang siapa yang menjaganyaia selamat. Barangsiapa menghilangkannya (tidak mengamalkannya) hancurlah ia.

Begitu besar faidah atau keutamaan sabar. Pantas seorang Luqman yang bijak menasihati anakknya dengan memberikan pesan yaitu sabar. Dalam hadits di atas dikatakan juga siapa yang sabar akan selamat dan siapa yang tidak sabar hancurlah ia. Ini menandakan bahwa begitu pentingnya sifat sabar.

Dalam tafsir Jalalain membahas sabar dalam beramar ma'ruf nahi mungkar. Sabar dalam mendakwahkan kebaikan dan mencegah keburukan. Namun penulis lebih kepada umum melihat makna pesan Luqman yaitu sabar. Sabar memiliki banyak pengertian dan tujuan. Dalam konteks ayat tersebut sabar lebih khusus dalam melakukan amar ma'ruf nahi mungkar.

\section{Larangan Sombong}

Sombong yang dimaksud dalam tafsir Jalalain juga diperjelas dengan singkat bahwa berlaku sombong dalam berjalan sangat dibenci, karena itu bisa membuat orang disekeliling menjadi tersinggung. Sombong adalah sifat yang sangat di benci oleh Allah SWT. Sifat sombong merupakan sifat yang pertama kali ada dalam sejarah. Penulis mengatakan demikian karena jika 
dilihat dari sejarah diciptakannya Nabi Adam as, disanalah timbul sifat tersebut yaitu ketika Iblis disuruh sujud kepada Adam oleh Allah SWT, Iblis enggan alias angkuh sombong tidak mau bersujud. Iblis menganggap dirinya lebih baik dari adam. Disitulah timbul sifat sombong yang keluar dari diri Iblis.

Dilihat dari sejarah tersebut, Luqman sangat menganjurkan kepada anaknya agar tidak berlaku sombong atau tidak berlaku Iblis. Sebab, sombong adalah pangkal dari segala kejahatan, keburukan dan kemaksiatan.

Sesuai dengan penulis paparkan pada bab temuan dan data bahwa dikatakan, Rasul bersabda, Tidak akan masuk syurga seseorang yang di dalam hatinya terdapat kesombongan seberat debu. Dilihat dari hadits tersebut sangat jelas besar bahayanya sombong. Sekedar seberat debu aja memilki sifat sombong tidak akan masuk syurga, bagaimana dengan sombongnya Iblis laknatullah.

\section{Sederhana dalam Berjalan}

Dalam tafsir Jalalain yang ditulis oleh imam Jalaluddin al-Mahalli dan imam Jalaluddin as-Suyuthi bahwa maksud dari sederhana dalam berjalan adalah ambillah sikaf pertengahan dalam berjalan, yaitu antara pelan-pelan dan berjalan cepat, harus tenang dan anggun.
Berjalanlah dengan sederhana maksudnya adalah berjalan dengan merendah kan hati supaya tidak timbul jiwa sombong dan angkuh. Kemudian harus tenang dan anggun maksudnya ketika berjalan baik dalam bepergian maupun dalam pergaulan selalu ciptakan ketenangan, jangan tergesa-gesa dan akhirnya dilihat dengan penuh sopan dalam berjalan karena itu maksud dari anggun dalam berjalan, enak dilihat ketika berjalan.

\section{Lunakkan Suara Dalam Berbicara}

Orang yang berbicara tanpa memiliki adab atau sikaf maka pembicaraan tersebut akan sia-sia bahkan akan merugiakn diri sendiri dan orang lain. Berbicara atau berkomunikasi memiliki aturan dan tata cara. Segala sesuatu di dunia ini telah diatur oleh yang Maha Kuasa, yakni Allah SWT. Ketika bekomunikasi dengan orang punya aturan, baik dengan anak kecil, remaja, dewasa, orang tua, guru dan lain sebagainya telah diatur pula oleh agama.

Salah satu pesan dari Luqman dalam konteks ayat dalam tafsir Jalalain adalah Lunakkan suara dalam berbicara atau berkomunikasi. Dalam pergaulan juga komunikasi sangat menentukanberhasil tidaknya suatu tujuan atau makna pesan yang disampaikan. Sikaf yang harus 
dilakukan dalam bekomunikasi adalah dengan cara lemah lembut, sopan dan tidak keras.

\section{Kesimpulan}

Diantara pesan yang terkandung dalam Surat Luqman mulai dari ayat 12-19 menurut Imam Jalaludin Mahalli dalam tafsir Jalalain yang menjelaskan secara terperinci baik dari kata-katanya dan kalimatnya. Pesan yang disampaikan Luqmanul Hakim pada ayat 12-19 terlebih juga diawali dengan sosok keperibadian Luqman, tetapi dijelaskan dengan cukup singkat. Dalam tafsir jalalain dijelaskan dengan tekhnik penerjemahaan ayat.

Dalam tafsir Jalalain ini juga dijelaskan lebih rinci yang dimulai dengan mengartikan potonganpotongan ayat kemudian dijelaskan menurut Imam Jalaludin al-Mahalli. Pesan yang terkandung dalam ayat al-Qur'an akan lebih mudah dilihat, dan mudah untuk diingat mana kalimat pesan dan mana kalimat penjelas.

Sebelum kepada pesan yang terkandung, Imam Jalaludin dalam tafsirnya pada bab temuan dan data menjelaskan makna ayat 12 yaitu

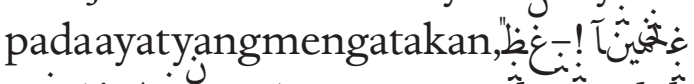

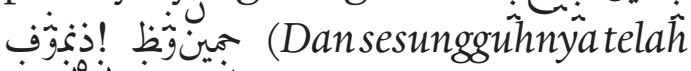
kamiberikan kepada Luqman hikmah) maksudnya adalah ilmu, agama dan tepat pembicaraannya, dan kata-kata mutiara yang diucapkannya cukup banyak serta diriwayatkan secara turun temurun.

Imam jalaludin al-Mahalli berpendapat bahwa maksud dari "hikmah" adalah ilmu, agama, dan pembicaraan yang tepat. Sehingga seorang Luqman dijuluki dengan al-Hakim. Kemudian baru kepada perintah bersyukur kepada Allah dan masuk kepada pesan komunikasi. Tafsir Jalalain ini merupakan tafsir yang sudah tua dan masih popular dikalangan ilmuan maupun pelajar.

Pesan yang pertama Luqman dalam tafsir Jalalain adalah larangan menyekutukan Allah. Cara penyampaian pesan tersebut dengan menggunakan adab yang penuh sopan. Dalam bab temuan dan paparan data dikatakan

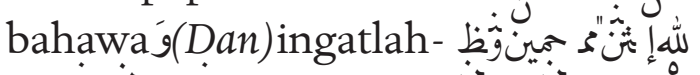
ف (KêtikaLuqman berkata kepada Anaknya,diwaktu ia menasihatinya: "Hai Anakku) lafadz «Yabunayya»adalah bentuk tashghir, yang dimaksud adalah memanggil anak dengan nama kesayangannya

Dengan kata dan etika penyampaiannya seorang komunikan akan cepat menerima pesan dengan baik. Penulis menganalisa bahwa cara penyampaian Luqman sungguh sopan dan indah karena dengan cara penyampaian pesan cepat diterima. Kemudian pesan selanjutnya 
kewajiban berbakti kepada orangtua. Dalam tafsir ini dikatakan غُغْجش

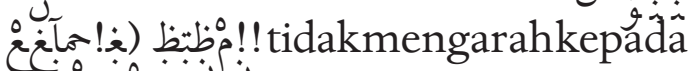
anak Lựman dalam wasiatnya tetapi kepada semua manusia untuk berbakti kepada orang tua.

Kemudian pesan selanjutnya menurut Imam Jalaludin alMahalli yaitu perintah mendirikan sholat, berbuat baik dan mencegah kemungkaransertabersabarterhadap apa yang menimpa seseorang khusus dalam konteks ayat tersebut yaitu sabar dalam beramar ma'ruf nahi mungkar.

Kemudian pesan selanjutnya menurut Imam Jalaludin al-Mahalli dan as-Suyuthi adalah larangan bahaya sombong. Maksudnya adalah sombong dalam bejalan, sehingga memberikan solusi agar sederhana dalam berjalan dan rendah dalam berbicara, dan pesan yang disampaikan akan diterima oleh komunikan. Seseorang yang berjalan tanpa ada sopan santun maka akan terjadi ketidakharminisan dalam berkomunikasi. Efek yang akan ditimbulkan adalah miskomunikasi atau negatif. Sebab dalam agama diajarkan sesuai denga pesan Luqman tersebut jangan berlagak sombong, tetapi sederhanalah.

Penulis menganalisa dalam tafsir Jalaludin ini penafsirannya dengan cara menguraikan kata perkata, dan diterjemakan langsung serta dijelaskan maknanya oleh Imam Jalaludin al-Mahalli. Penulis melihat tafsir ini cukup singkat tanpa menguraikan makna secara luas.

Selanjutnya pada ayat 19 dijelaskan kesederhanaan dalam berjalan dan sopan santun dalam berkomunikasi dengan penuh etika yang baik. Jangan terlalu angkuh dalam berjalan dan jangan terlalu keras dalam berbicara tanpa makna atau sia-sia dan itu dapat merugikan diri sendiri dan orang lain. Sebab seburuk-buruk suara adalah suara Keledai. Itulah yang diibaratkan oleh Luqmanul Hakim kepada orangorang yang berbicara melampaui batas atau sia-sia.

Berdasarkan hasil pembahasan di atas, maka dapat ditarik kesimpulan sebagai berikut:

1. Analisis pesan Luqmanul Hakim terhadap anaknya dalam alQur'an surat Luqman ayat 12-19 Berdasarkan Tafsir Jalalain adalah antara lain: Larangan berbuat syirik, Berbaktikepada ibu bapak, anjuranuntukmendirikan sholat, amar ma'ruf nahi mungkar, anjuran untuk bersabar, larangan bersifat sombong atau angkuh, sederhana dalam berjalan dan lunakkan suara dalam berbicara.

2. Pandangan ulama tafsir (Imam Jalaludin al-Mahalli dan Imam Jalaluddin as-Suyuthi) tentang 
pesan komunikasi Luqmanul Hakim Terhadap Anaknya dalam Al-Qur'an ayat 12-19 adalah bersyukur terhadap nikmat Allah SWT, kewajiban berbakti kepada orang tua (lebih menjelaskan kepada ibu yang telah mengandung, melahirkan dan merawat), anjuran untuk mendirikan sholat, selalu dalam pengawasan Allah SWT, beramar ma'ruf nahi mungkar, bersabar, larangan sombong dan sopan dalam beretika, serta lunak dalam berkomunikasi tidak kasar atau keras.

\section{Daftar Pustaka}

Anty, "prinsip komunikasi islam”. dalam http://www. risalahislam.com, 2017. Di akses tanggal 28 September 2017 pukul 14.10 wita

Danus Ardiansah, "Hakikat Dalam Pesan Komunikasi". dalam http: / / www.academia. edu/9036594 di akses tanggal 2 oktober 2017 pukul 06.20 wita

Hafied Cangara, Pengantar Ilmu Komunikasi, (Jakarta: RajaGrafindo Persada)

Kementrian Agama RI, Al-Qur'an dan Terjemahan Edisi Trasliterasi, (Solo: Tiga Serangkai Pustaka Mandiri, 2015)

Mudjab Mahali, Asbabun Nuzul, (Jakarta: RajaGrafindo Persada, 2002)

Onong Uchana Efendy, Ilmu Teoridan Filsafat dan Teori Komunikasi, (Jakarta: Citra Aditya Bakti)

QS. Luqman: 13 (al-Qur'an dan terjemahan edisi transliterasi) 